\title{
Bullring: A case study of retail-led urban renewal and its contribution to city centre regeneration
}

Received (in revised form): 2 February 2006

\begin{abstract}
John Emery
joined Hammerson in 1989. In 1999 he was appointed Director for Development and in 2001 was charged with the responsibility for the development of Bullring on behalf of The Birmingham Alliance. In 2005, Jon was appointed Hammerson's Head of UK Development and a UK board director. During his time with Hammerson, Jon Emery has been responsible for managing a number of high profile developments for the company, including 99 Bishopsgate in London EC2 and Globe House on London's Embankment. Between 1997 and 2000, Jon was responsible for the awardwinning riverside retail and leisure development in Reading, The Oracle. Since the completion of Bullring, for which he was development director, Jon has been responsible for leading the project teams involved in large-scale retail-led regeneration projects for Hammerson at Bristol with The Bristol Alliance, and at The New Retail Quarter, Sheffield, with Sheffield One and Sheffield City

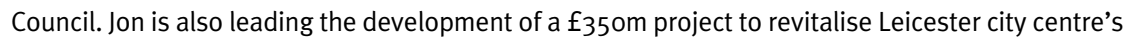
retail quarter with a major new mixed-use development, which is to be completed in 2008.
\end{abstract}

\begin{abstract}
Just ten years ago, Birmingham was seen as the ugly sister of British cities: run-down, congested and unappealing to visitors. Thanks to a series of pioneering urban regeneration projects, the city is being rapidly transformed, with canal-side offices and restaurants at Brindleyplace rubbing shoulders with buzzing bars on Broad Street and the exciting Symphony Hall. However, one problem remained: the city's limited retail offer was not on a par with the international standard of its business and cultural facilities. One of Birmingham City Council's key objectives was to redress this balance, and more importantly, to stem the flow of shoppers and the associated economic benefits from travelling out of the city. Here, developer Jon Emery discusses Bullring - Birmingham's new retail and leisure destination and its largest city centre regeneration project to date. The lessons learned from Bullring are already shaping the next generation of city centre urban regeneration projects. One vital ingredient stands out: the way in which the city as a whole embraced and supported the creation of Bullring. The experience has shown that future regeneration projects need to articulate an appetite for change if success is to be achieved and sustained.
\end{abstract}

John Emeryjon Emery Hammerson $\mathrm{pc}$ 100 Park Lane London W1K 7 AR, UK Tel: + 4402078871000 Fax: +4402078871090 E-mail: jemery@hammerson.co.uk

\section{Keywords:}

working in partnership, inclusivity, design excellence, shaping a new urban landscape for city living, wider benefits

Journal of Retail and Leisure Property (2006) 5, 121-133. doi:10.1057/palgrave.rlp.5100020 


\section{PARTNERSHIP}

In 1999 three leading UK property investors and developers formed The Birmingham Alliance to take forward the redevelopment of one of the City's most notorious eyesores - Bullring. It was a groundbreaking move for the industry. Until then, the rival companies had been vying to develop their individual interests in Birmingham city centre - Bullring, Martineau Place, and Martineau Galleries. The result had been a stalemate. Potential occupiers of the separate proposed schemes, each of which had significant merits, could not wait for the impasse to be resolved. They set up shop elsewhere in the region.

Birmingham was losing out. Retail-led schemes are increasingly being viewed by city leaders as one of the most effective tools in boosting the economic status of their towns and cities, triggering wider regeneration and investment. The opportunity for Birmingham seemed to be faltering. It was time for radical political intervention.

\section{A ground-breaking approach to public-private partnership}

Under the guidance of the Head of Economic Development and Chief Executive of Birmingham City Council, a partnership was brokered between Hammerson plc, Henderson Global Investors Ltd and Land Securities Group PLC that would provide the catalyst for subsequent joint ventures across the industry. The sharing of risk, and reward, has become the mantra for property developers. However, the most attractive aspect of the partnership was that it concentrated the focus on one specific solution - a single-minded uncompetitive approach to the process of change.

The three partners merged their individual interests and agreed to have an equal third share in the three schemes. Each contributed their property assets and agreed on a phased development programme of the three complementary schemes, which covered some 40 acres in the city centre.

First came Martineau Place, for which Land Securities was the development manager. The $£ 100 \mathrm{~m} 17,000 \mathrm{~m}^{2}$ retail scheme opened in November 2001. Bullring, the $110,000 \mathrm{~m}^{2}$ scheme for which Hammerson was development manager, was the second flagship phase and opened in September 2003. The third and final phase, Martineau Galleries, is yet to begin, but the proposed redevelopment of the 14-acre site will complete the retail regeneration planned for Birmingham city centre (Figure 1).

The partnership approach did not end there. In reality, The Birmingham Alliance comprised the two publicly quoted property companies and one very large fund manager of private investments, with Birmingham City Council as the fourth partner. The relationship with the council was three-fold: as landowner, planning authority and highways control. As a public-private partnership it represented a true marriage and alignment of commercial, social, economic and community interests.

As part of an early agreement with Hammerson, Birmingham City Council included as a development obligation the continued operation of the two indoor markets and also the outdoor market and their relocation to new premises. The obligation came about as result of concerns from market traders that the city's historical precedent for the site, which was established in 1166 when Birmingham was first granted a royal charter to have its own market, would be continued. The result was a $£ 6 \mathrm{~m}$ 


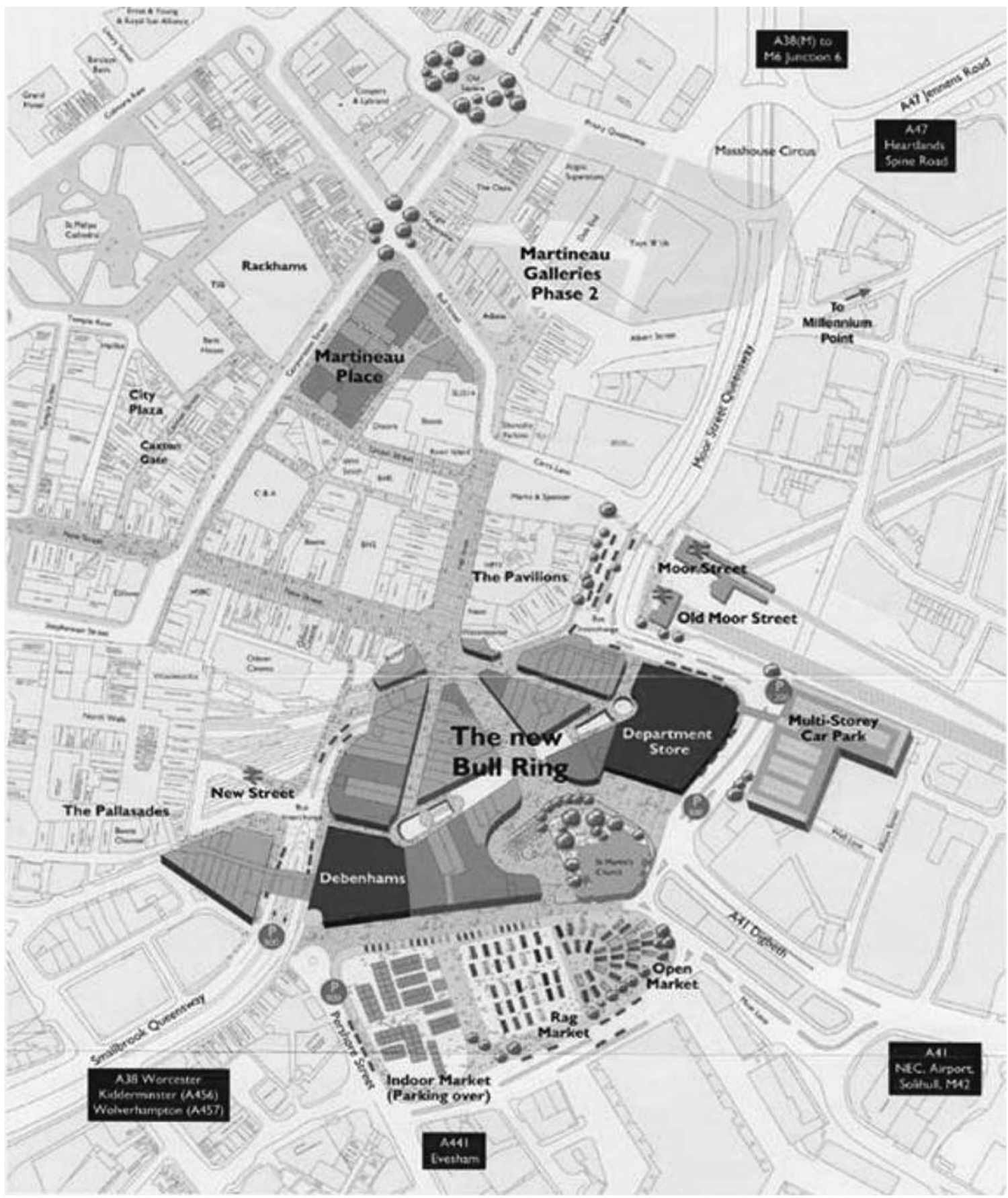

Figure I: Bullring, Martineau Place and Martineau Galleries — location map

investment, which saw the construction of a new $5,000 \mathrm{~m}^{2}$ state-of-the-art indoor market to accommodate 90 traders. This first stage of development was completed and opened in September 2000.

\section{INCLUSIVITY}

Regeneration carries a tremendous responsibility. Carried out the right way it can make a real and lasting difference to people's lives. It literally 
shapes the environment in which people live, work, shop and spend their leisure time. Rightly, this type of development raises strong emotions, and different stakeholders have varying and sometimes conflicting views on what they would like to see happen. However, a city must have the ability to facilitate and deliver in partnership with the developer. Birmingham had all these abilities.

Harnessing these abilities was vital to the project, but key to managing the process of change lay in The Birmingham Alliance's inclusive approach. From the outset they made a commitment to capturing the hearts and minds of all interested parties and stakeholders, and to balance the varying needs of all, from politicians, the local community, business organisations, public services, existing retailers in the city to potential occupiers.

This approach was essential in view of the lengthy disruptions brought about during the three-year construction period. While the developers sought to minimise these, it was felt that communicating the processes required to achieve the end product would promote greater understanding and tolerance among all these different groups. Ultimately, they became Bullring's most effective ambassadors and when the scheme opened Birmingham's city pride could not have been greater.

\section{Communicating the vision}

At the core of this inclusive approach was the sharing of the Bullring vision. To this end a lengthy and detailed consultation process was undertaken, and a comprehensive public awareness programme was implemented to embrace every stakeholder sector.

The Birmingham Alliance carried out its own publicity and marketing, launched a campaign of public speaking, initiated focus groups and direct marketing, and introduced a leading-edge website, which was linked to webcams on site showing construction progress.

A professionally produced publication 'Bullring Magazine' was also published at key stages of the project's development. Widely distributed, the magazine included lifestyle articles, contributions from the consultant teams working on the project, reports on construction progress, job opportunities as well as updates on new retailers opening at the scheme.

Alliances were also forged with Birmingham's tourist and relocation advisory organisations such as Marketing Birmingham and Birmingham Forward, which were encouraged to take an active and vocal role in supporting the development of Bullring. School and community programmes and exhibitions were initiated through Rotunda OneFive, so named because of their base on the 15th floor of Birmingham's landmark Rotunda office tower, also owned by The Birmingham Alliance. Regular site tours and open days for the public were organised at milestone stages during construction, and extensive media coverage was generated as a result of weekly one-to-one meetings with key press and broadcast media.

The marketing and public relations programme for Bullring was one of the most successful for a UK shopping destination development. The scheme generated more television and radio coverage, more column inches in trade magazines and industry literature than any other retail 


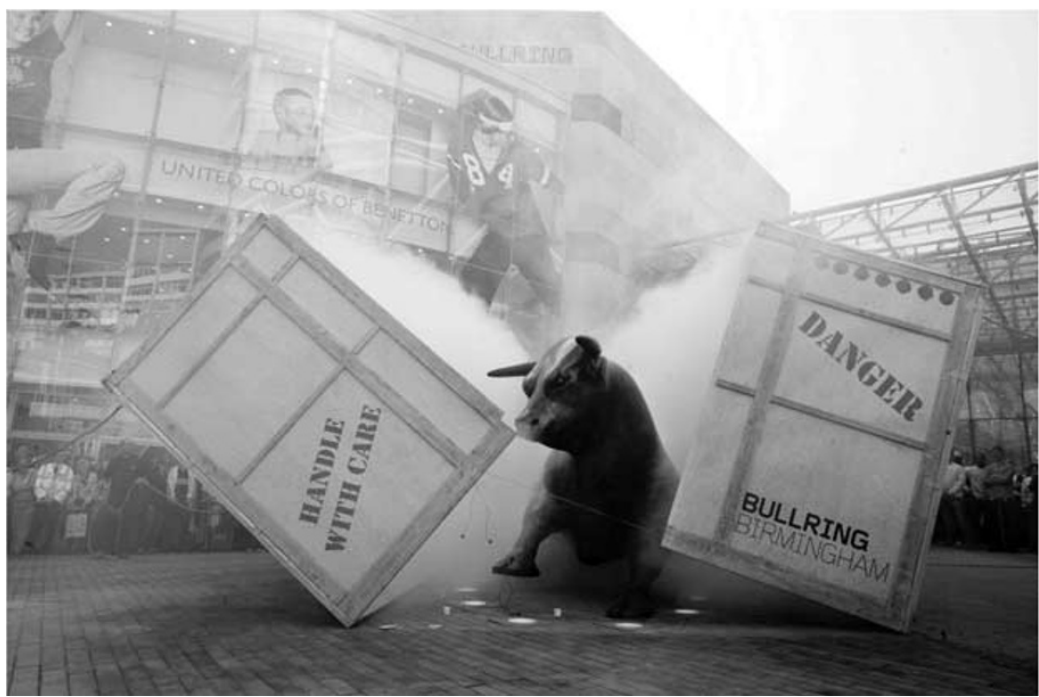

Figure 2: 'Bully' — Birmingham's new mascot

project. In total, over 1,400 articles were published about the opening of Bullring, and the event was covered by 21 different national and international radio and television networks.

\section{Creating art for the community}

Another example of The Birmingham Alliance's inclusive approach, which merits more detailed explanation, was Bullring's public art programme. While public art has long been a feature of commercial development, its contribution is often viewed with some scepticism by the community it is intended to benefit. At Bullring, The Birmingham Alliance invested in a $£ 2 \mathrm{~m}$ programme of artwork for the scheme's public spaces. It was structured to attract the creative talents of both local and international artists and designers. More importantly, each piece was to be relevant to its proposed location, and draw on Birmingham's cultural and historical heritage.

The results have been extraordinarily well received. One of these pieces, a twice-life size bronze bull positioned at a main entrance to Bulling has been adopted by Birmingham as the new city mascot (Figure 2). The patina on his nose has been rubbed to a shine from the number of people giving him an affectionate pat as they pass. Miniature two-inch high replicas - produced in response to public demand - were sold out in two days. He is known as 'Bully' and his image now adorns the masthead of The Birmingham Post.

Other artworks around Bullring include a cluster of three light wands, and these $30 \mathrm{~m}$ high masts have become a landmark beacon, which is visible across the city centre. The sound of cascading water is a feature of Bullring's public piazza where three giant glass cubes are lit in constantly changing hues of pink, orange and blue. Another installation is a $120 \mathrm{~m}^{2}$ glass mural, while a series of steel panels depicting the history of Birmingham line a pedestrian walkway in the form of railings. 
The art programme also included the restoration of several Birmingham landmarks. A five-tonnes bronze statue of Admiral Nelson dating from 1809 was restored and reinstated in its historically prominent position overlooking Bullring's main piazza. At centrestage within this new civic space is the newly restored St Martin's Church, towards which The Birmingham Alliance contributed $£ 2 \mathrm{~m}$ of 'match' funding. Since the opening of Bullring, the congregation at the church has doubled, and visitor numbers now average 25,000 people a week.

\section{Tenant mix principles}

Engaging with the local community was one strand of the challenge faced by The Birmingham Alliance, but a new community also needed to be convinced to take part in Birmingham's regeneration - that of incoming retailers to the new scheme.

Typically, retailer confidence in a scheme is driven by a number of factors, not least of which is the developer's ability to create a viable trading proposition. Exhaustive research into a location's demographic profile, MOSAIC profiling and catchment studies are all essential tools in the development of commercial centres. Birmingham was unusual in that, despite its status as Britain's second largest city, it did not have a retail offer to match its reputation as a leading centre for business and culture. Birmingham suffered from a large part of its core catchment shopping elsewhere in the West Midlands. A coordinated approach was crucial to preventing a negative impact on the city's existing retail offer.

The goal of The Birmingham Alliance was clear: to transform a neglected part of the city centre into Europe's most vibrant quality retail environment, as well as a meeting point and a new civic heart for the city. Birmingham is the UK's second largest city by population, yet until the revitalisation of Bullring it was fifth in terms of retail space. It is now second. The Birmingham Alliance set themselves the task of dramatically changing the face of retailing in the West Midlands by delivering Europe's largest city centre retail regeneration project - to attract the $7.2 \mathrm{~m}$ consumers within an hour's drive time back to the city.

Securing the right retail mix for Bullring was vitally important, and critical to this was attracting the main anchor tenants. Debenhams had already reached an agreement with Hammerson to take space at Bullring in the days before the formation of The Birmingham Alliance. The department store retailer had been persuaded to return to Birmingham after a 20-year absence in the city, and chose to launch the first of its new 2010 concept stores at Bullring.

However, it was Selfridges that captured the public imagination. As high-profile tenants go, Selfridges could not be bettered. The London department store had recently been refurbished and re-styled as a 'house of brands'. At the same time the retailer had embarked on a series of cutting-edge promotions designed to appeal to a younger, more lifestyle focused, and designer label-conscious customer.

The prospect of taking this new concept to the UK's second city was hard to resist, and Selfridges embraced the challenge by commissioning a 


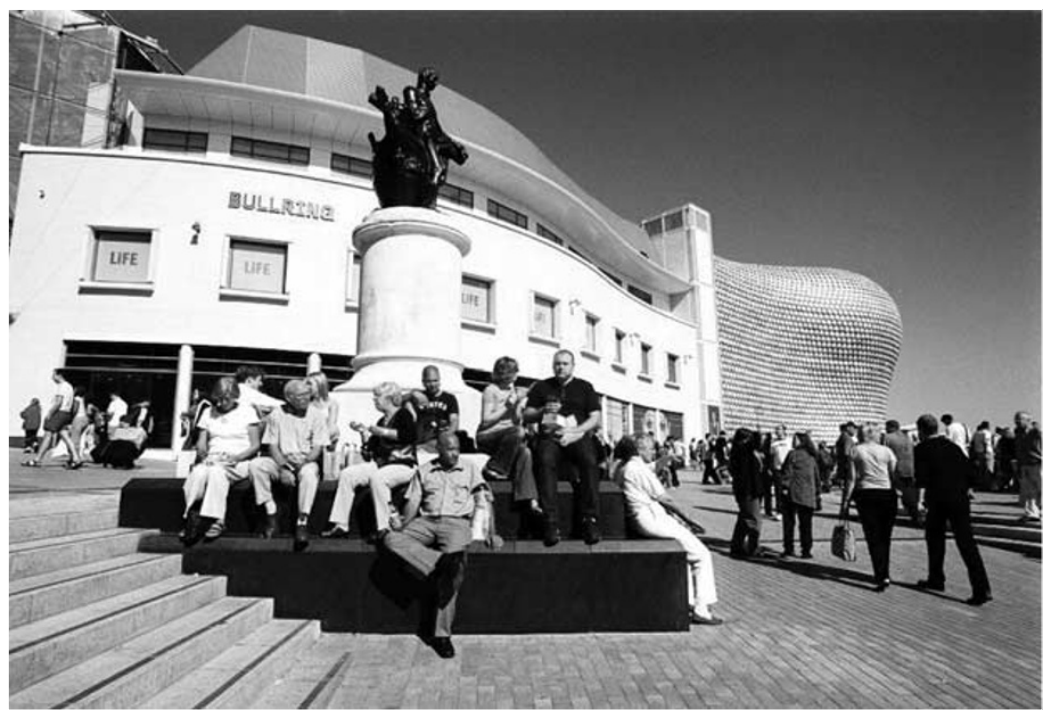

Figure 3: Old and new — Admiral Nelson overlooks Selfridges in the background

daring and futuristic design for its new department store building. It was the ultimate means in which the retailer used its real estate investment as a three-dimensional advertisement for its brand values - and it brought a dramatic fashion statement to a city in much need of rejuvenation (Figure 3).

The design of Bullring itself was a major factor in securing a vibrant and exciting tenant mix. Its open street atmosphere appealed to a number of retailers not typically associated with shopping centre environments, thereby giving the scheme its unique offer. Another key part of the tenant mix strategy was to create a series of 'mini-pitches' for retailer categories by using Bullring's mall pattern to cluster similarly branded concepts together, with Debenhams and Selfridges positioned at opposite ends of the scheme.

Each of the scheme's three trading levels were defined by a different design treatment to provide a distinctive personality in terms of retail mix. High street fashion and catering occupied the lower level. Young fashion and lifestyle retailing occupied the mid-level, and aspirational fashion was located on the scheme's upper level. This formula was mirrored by the department stores, so that each of their own store levels became natural extensions of the type of retail mix designated for each particular mall.

At the time of its opening, Bullring had attracted over 70 new retailers to Birmingham for the first time. Since then, and with the additional development of Bullring Link, the $6,600 \mathrm{~m}^{2}$ redevelopment of the former Wades furniture store building which also formed part of the Bullring estate, more retail newcomers have opened at the scheme. This final element, which comprises 20 shop units, provided the opportunity for a range of independent operators and niche retailers to take part in Bullring's success.

While some market commentators predicted that the opening of Bullring would drain retail activity from other parts of the city. This has 
proved not to be the case. Out of the total number of retail tenants at Bullring, $26 \%$ opened a second or third store in the city by taking a unit within the scheme.

Of those retailers to have relocated to Bullring, the majority of their former stores are now occupied by an influx of new brands to the city. Many other retailers have 'raised their game' to capitalize on the footfall generated by Bullring — a prime example being House of Fraser’s $£ 30 \mathrm{~m}$ refurbishment.

With the opening of Bullring, Birmingham saw a $40 \%$ increase in its city centre retail offer, and boosted the city's position to England's best retail destination outside London's West End. Its success has been overwhelming. In its first year of trading, Bullring attracted 36 million visitors, exceeding even the most optimistic forecasts by ten million.

\section{DESIGN EXCELLENCE}

The challenge facing The Birmingham Alliance in developing Bullring was formidable. The site was spread over 26 acres in the centre of the city, and fell $20 \mathrm{~m}$ in level from north to south. Abutting the site to the north were two existing prime shopping streets and a listed building, Birmingham's landmark circular office tower, the Rotunda, considered to be an outstanding example of 1960s architecture. To the south of the site was the 18th century gothic landmark of St Martin's Church and the three markets. To the east of the site was Moor Street Station, and immediately to the west, with Victorian train tunnels running beneath the site itself, was Birmingham's main intercity terminus, New Street Station (Figure 4).

Creating a design that would allow all these elements to continue to function during the development process was one aspect of the challenge. The other was to ensure that all of these elements would ultimately form an integrated whole.

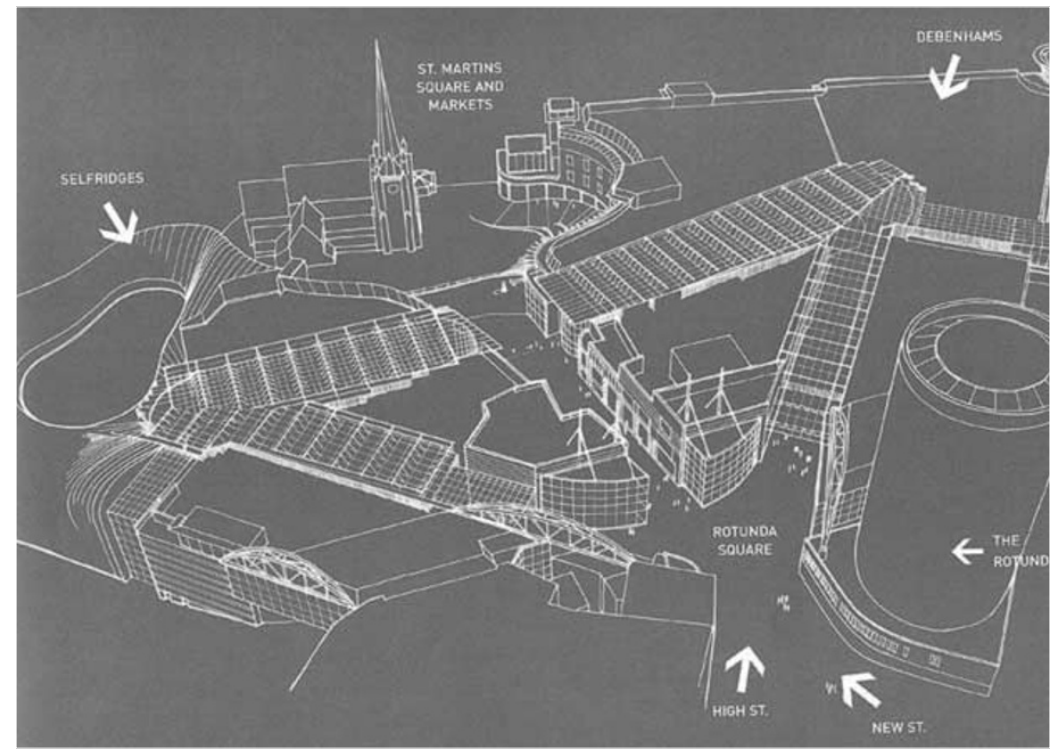

Figure 4: Plan showing key thoroughfares 


\section{Connecting the city}

The resulting design of Bullring is characterised by its permeability and the way in which open spaces and walkways throughout the three principal trading levels link in to the city centre to form a natural extension to Birmingham's existing prime retail pitch. The natural gradient of the site, falling some $20 \mathrm{~m}$ from north to south, was integrated into Bullring's design so that each trading level had its own access to a ground floor entrance.

One of the biggest challenges in terms of integrating the centre back into the city of Birmingham was the breaking of the 'concrete collar' of ring roads surrounding the site. This was overcome below ground by cutting a new tunnel for use by taxis and buses to connect the two train stations. Above ground, an innovative engineering solution was used to bridge the road and railway tunnels below with four dramatic steel bowstring trusses from which Bullring's new buildings are suspended. This allowed for a seamless connection between the city's two main shopping streets and a newly created pedestrian boulevard called St Martin's Walk.

By cutting open what had been for decades 'no go' areas, the new connecting thoroughfares — such as the pedestrian streets in the mall areas and St Martin's Walk — Bullring's design reinstated historic street patterns and restored dramatic city views of St Martins Church and the markets beyond.

Bullring comprises two buildings, one on either side of the pedestrian boulevard of St Martin's Walk, each stepping down the $20 \mathrm{~m}$ slope of the site. The two buildings are rendered differently so that the overall sense is one of a collection of individual buildings. The scheme itself is crisscrossed by pedestrian streets, some open to the sky, others seemingly open but covered by a 'floating' 7,000 $\mathrm{m}^{2}$ glazed roof (Figure 5).

Three new public spaces were also introduced at key points throughout the scheme. Rotunda Square to the north of the scheme is where the old city meets Bullring. Here, seven streets converge: the two new shopping streets of Bullring, St Martin's Walk, Birmingham's existing prime retail streets - High Street and New Street — and two other existing streets, which feed into the two railway stations. The second public space is $\mathrm{St}$ Martin's Walk. This wide pedestrian boulevard is lined by restaurants and cafes and has become a continental style meeting point for the city. St Martin's Walk opens out into the third and most dramatic of Bullring's public spaces - St Martin's Square. This grand square is the backdrop for St Martin's Church, which sits at its heart.

It is not just the way Bullring connects physically with the rest of the city that has made it so successful. Bullring's 'e-factor', its IT and software management systems, is one the most advanced to have been developed for a shopping centre environment.

All Bullring's retailers are connected to a centrally controlled intranet system via their own dedicated computer terminals. From these, retailers are e-enabled to communicate with Bullring's centre management, as well as with customers through in-mall touch screens. Retailers also receive information on the intranet direct from centre management such as safety alerts, maintenance programmes and Bullring events. 


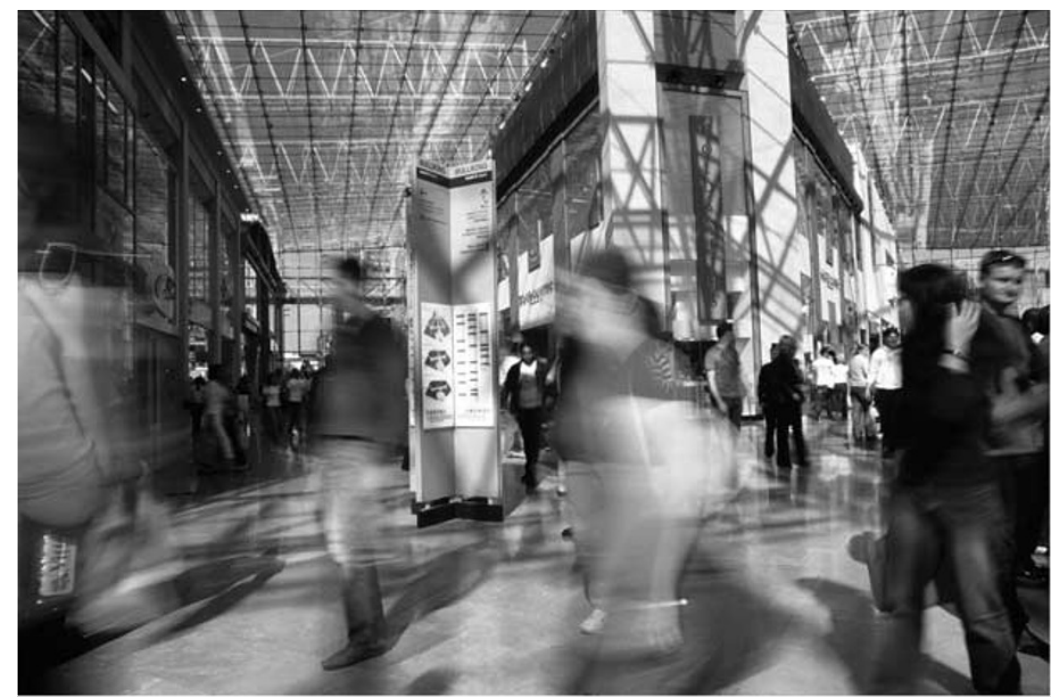

Figure 5: Skyplane roof

Bullring's shoppers can also experience the 'e-factor' through 22 freestanding in-mall electronic touch screens (Figure 6). From these, visitors can access a range of information about job opportunities within the scheme, its retailers, product launches and events, news, real-time travel information and the shopping environment.

\section{SHAPING A NEW URBAN LANDSCAPE FOR CITY LIVING}

Taken together, the generosity of the public realm combined with a stimulating mix of architecture and a permeability allowing access from numerous points around the scheme are the distinguishing features of Bullring's design. These elements have become the model for future city centre regeneration. The focus is on people and on experience, not on buildings.

This focus on 'experience' has become something of a mantra for developers post-Bullring. Future urban renewal projects will incorporate a higher proportion of mixed uses as towns and cities seek to create environments that mimic the fundamental values and strengths of naturally evolved urban centres.

\section{'Experience' destinations}

These centres will become more 'experience' focused city-living environments, designed specifically for the communities that they are intended to serve. Embracing a full range of activities from living, shopping, working, learning and entertainment, this new generation of 'experience destinations' is already being shaped for cities such as Bristol, Leeds and Sheffield.

Key to their success is the integration of the existing attributes unique to each location, which reflect the scale and diversity of its current streetscape. Their principal characteristics will be a series of distinctive and individually designed buildings, which are integrated into their 


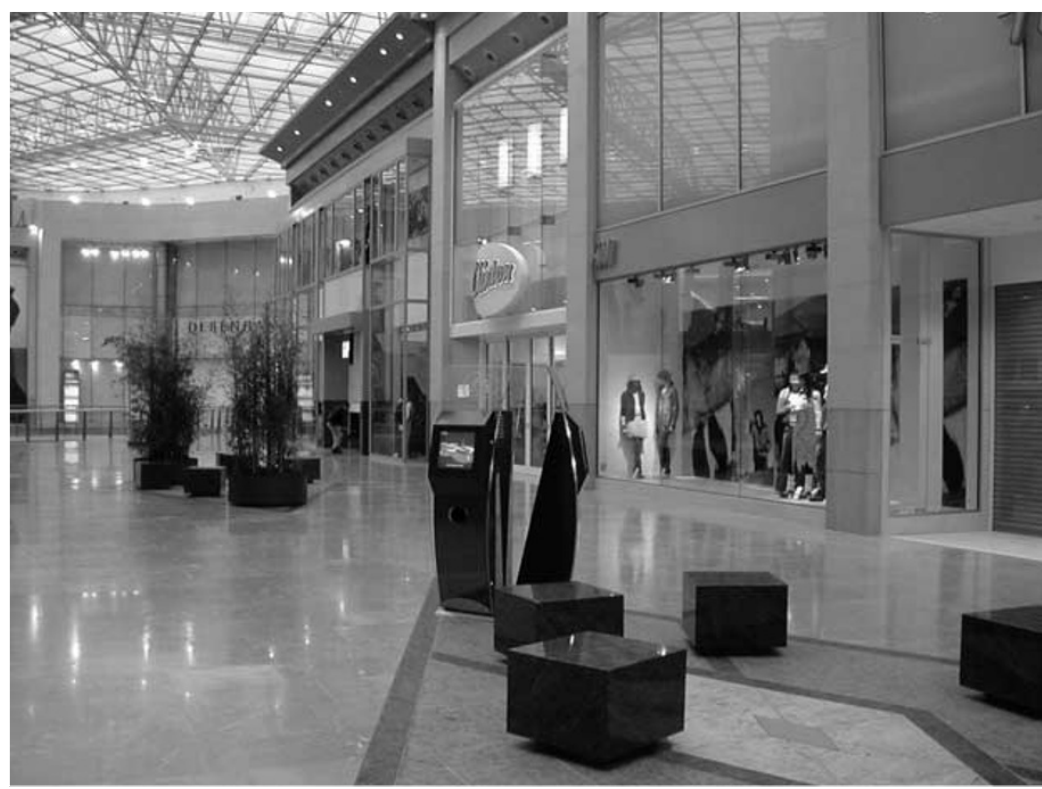

Figure 6: In-mall touchscreens

environments through the sensitive use of scale and building materials, and are connected to each other via a sequence of streets, squares and public spaces. Public transport facilities will also be increasingly incorporated as integral elements of these environments.

Ensuring that the mix of uses work together without any one being detrimental to the other is a more complex challenge. Designing for city living presents a wider range of design issues addressing access, services, fire safety and noise control. The presence of residential accommodation brings with it a new set of requirements and a complementary mix of facilities. All of these elements contribute to a location's vibrancy, fostering a sense of community, which drives its success as an attractive destination.

\section{THE WIDER IMPACT OF BULLRING}

The benefits to Birmingham through the opening of Bullring have been much broader than simply re-establishing the city's prominence as a shopping destination. Over 8,000 jobs were created during the project's lifetime and, since opening, Bullring has generated thousands more employment opportunities. The retail industry has become a major employment sector in Birmingham as more retailers have been encouraged to open stores elsewhere in the city.

Birmingham's tourist industry has seen significant benefits, with hotel operators in the city reporting an increase in weekend trade. In the first 12 months since Bullring opened hotel occupancy rates for weekend stays in the city overall rose by $8 \%$.

Public transport has also seen a marked increase in usage. Some $60 \%$ of visitors are choosing to travel by bus and train to visit Bullring, and train operators have reported a $7 \%$ increase in train usage. 


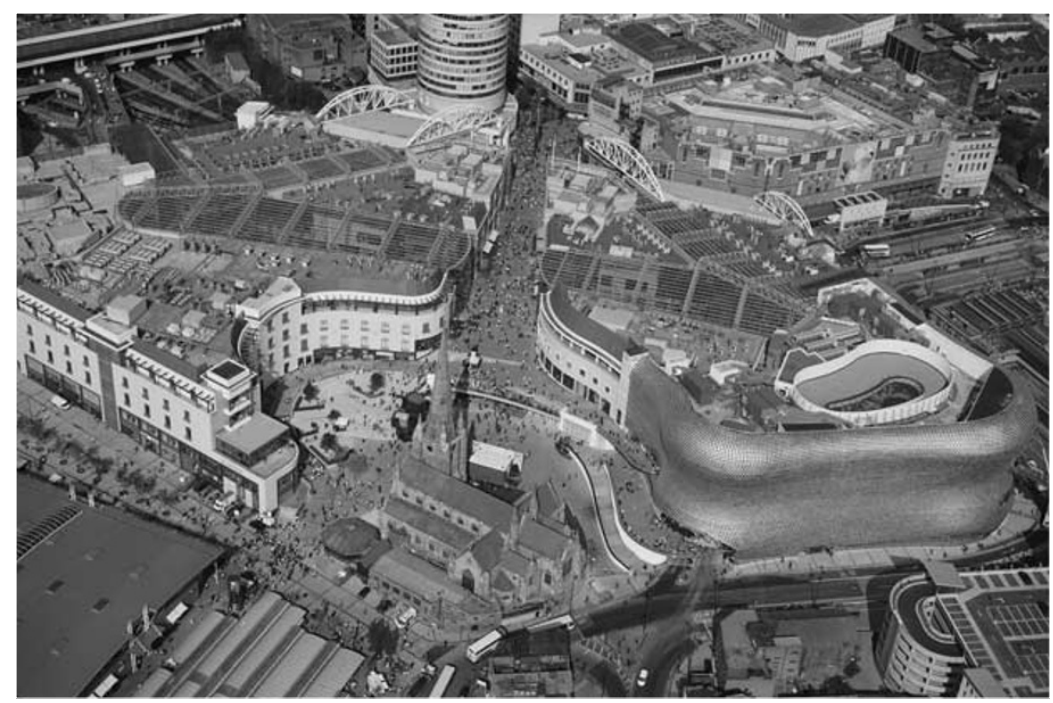

Figure 7: Bullring - aerial view

Independent research commissioned by The Birmingham Alliance has also shown that other retail destinations in Birmingham have benefited from Bullring, with $60 \%$ of visitors saying that they had visited, or intended to visit, other city stores and shopping centres such as House of Fraser, Marks \& Spencer, Pavilion Central and the Mall Pallasades. Birmingham's prime retail pitches along New Street, High Street, Union Street and Corporation Street have also seen a resurgence in retail lettings and the quality of these retail areas has been improved with an upgrading of the retail offer to complement the quality of choice at Bullring.

At Bullring itself, visitor numbers continue to exceed expectations, with an average of 670,000 per week. In its second year of trading, the scheme saw 38 million visitors, a 12\% increase on its first year. Bullring has repositioned Birmingham as a retailing powerhouse, and its iconic architecture has become the new visual identity for the city (Figure 7).

The Birmingham Alliance continues its commitment to Birmingham. The city is experiencing a major resurgence in city centre living and, as a final piece of the Bullring jigsaw, Birmingham's cylindrical 20-storey office tower building, The Rotunda, is being transformed into a landmark residential development through a partnership between The Birmingham Alliance and Urban Splash. Although the redevelopment will not be completed until 2008, all 232 apartments have already been sold off-plan. The new development brings a vitally important ingredient to Bullring's continued success as a true urban quarter incorporating places to live, work, shop and be entertained.

The former Edwardian station of Moor Street adjacent to Bullring has also been restored by The Birmingham Alliance. The ticket office has been reinstated in its original 1930s style and reopened after 16 years of non-use. The station is also to be brought back into full operational usage in 2007 to create a new gateway to Bullring and Birmingham from London Marylebone. 
Regeneration on this scale does not come cheap. In total, The Birmingham Alliance has invested over $£ 600 \mathrm{~m}$ on the schemes completed to date. In addition, it has required long-term drive and commitment, not just from the development partners, but from all the consultants involved in the project and, crucially from the city of Birmingham. From conception to opening, Bullring took ten years to complete. During that period changes were inevitable, but the founding principles of its success remained firm throughout: vision, partnership, inclusivity and design excellence. 